Article

\title{
On the Control of Low-Frequency Audible Noise from Electrical Substations: A Case Study
}

\author{
Edoardo Alessio Piana ${ }^{1, *(\mathbb{D})}$ and Nicolaas Bernardus Roozen ${ }^{2}[\mathbb{C}$ \\ 1 Department of Mechanical and Industrial Engineering, University of Brescia, 25123 Brescia, Italy \\ 2 Laboratory of Acoustics, Department of Physics and Astronomy, KU Leuven, Celestijnenlaan \\ 200D, B-3001 Heverlee, Belgium; bert.roozen@kuleuven.be \\ * Correspondence: edoardo.piana@unibs.it; Tel.: +39-030-371-5571
}

Received: 16 December 2019; Accepted: 13 January 2020; Published: 16 January 2020

check for updates

Featured Application: Reduction of the noise impact of electrical substations through a hybrid control strategy based on passive noise barriers and auditory masking.

\begin{abstract}
With the world facing the urgency of energy transition, the development of efficient and quiet electrical infrastructures is of topical importance in the construction of the environment of the future. The problem of noise from power distribution systems is often underestimated, although several works in the literature underline the effect of disturbance on the population, especially concerning the low frequency range. This paper overviews the issue of the low-frequency noise generated by electrical substations, from the experimental characterization of the source to the possible mitigation measures at the source, along the propagation path and at the receiver. Alongside the general presentation, a case study serves as a practical demonstration of the proposed methodological approach. It was found that in the investigated situation the main disturbance comes from the transformer at two low-frequency harmonics of twice the networking frequency. A traditional noise barrier is designed taking into account the strict size constraints imposed by technical compatibility with the electrical infrastructure, which limits its efficacy at low frequency. Noise masking with broadband signals can be a complementary solution to further reduce noise disturbance and contain it within prescribed limits. The evaluation of subjective response of the receivers to different mitigation solutions is made possible by the availability of the impulse response.
\end{abstract}

Keywords: noise barrier; power substation; transformer noise; low-frequency noise; noise masking

\section{Introduction}

The world is facing one of the greatest energy transitions of human history [1], in which electrification is tearing down the barriers that used to exist between sectors traditionally relying upon different fuels and infrastructures [2]. In the Ten-Year Network Development Plan by ENTSO-E [3,4] concepts like security supply, renewable energy source (RES) integration, resilience [5] and the renovation of the existing infrastructure are presented as key elements of the EU energy policy. If the energy distribution and transmission are evolving to new paradigms, the urban landscape is changing as well. In 1950 only the $30 \%$ of the world population was urban; now the value is almost doubled and, according to the United Nations, in 2050 it will reach the 68\% [6]. As a result, cities expand and what originally was the outskirts is presently absorbed in the urban area.

Power substations are a key element of the energy infrastructure. A substation is a node in the electric grid which performs one or more functions, such as connecting two high-voltage (HV) lines with the same or different voltage levels, performing voltage control and conversion, reactive power control or power factor correction, and regulating the power flow [7]. The acoustic compatibility with 
residential areas is particularly important because the generated noise can be very high $(75-85 \mathrm{~dB}(\mathrm{~A})$ $1 \mathrm{~m}$ far from the transformer case).

McDonald [8] discusses the noise of substations, pointing out that distance plays an important role, but it cannot be considered an absolute factor: if substations are closer to urban areas, noise is less attenuated but the background noise is higher than in rural areas where it can be as low as $20-25 \mathrm{~dB}(\mathrm{~A})$. Moreover, the attenuation of air depends on frequency, and thus it can change the spectrum of the noise over distance.

Passive methods to abate noise are mainly focused at the source or along the propagation path. The first group of measures encompasses careful design and operation of the infrastructure, including the choice of the location: the substation should preferably be built underground, or at least as distant as possible from residential centers, in large isolated areas with a high background noise. Sanders et al. [9] state that "if it is properly taken into account during the design phase", noise is not a problem in new installations, thus implying that indeed it might be an issue when not thoroughly considered, or in the case of expansion of existing installations, which are usually stretched to the limit. When designing or revamping a power substation, equipment with noise emissions below the manufacturer's standard can be required to reduce continuously radiated discrete tones [8], impulse noise [10] and corona discharge noise [11].

In particular, the transformer is the element that is more likely to raise complaints, especially when its rating is high. The transformer consists of three main parts: the primary coil and the secondary coil around the laminated core, and the air handling units. Noise generation in transformers is a vibro-acoustic problem, since Lorentz forces induced by the high currents flowing through the coils typically cause vibrations at twice the networking frequency and its harmonics. With a network frequency of $50 \mathrm{~Hz}$, tonal components at 100, 200 and $300 \mathrm{~Hz}$ are to be expected, which makes the problem of low-frequency noise a sensitive issue. Only a modest reduction in transformer noise can be obtained by acting on its construction, but at the price of dramatically increased cost (10-30\% of cost increase against noise abatement of 5-10 dB [12]) and inevitable power reduction. The "IEEE Guide for the Design, Construction, and Operation of Electric Power Substations for Community Acceptance and Environmental Compatibility" (IEEE 1127-2013) [13] encourages the use of field measurements and of computer simulations in situations where noise can be a concern, and admits that the cost implications of the noise control strategy may become a significant factor.

The most widely adopted control measure is the use of suitable shields and barriers made of bricks or gypsum panels, placed between the substation and the area to protect (vegetation is not considered in this context due to the modest attenuation in the low frequency range against the large thickness required and the safety issues connected to fire hazard and reduced visibility). The shields must be placed as close as possible to the source and must have a certain minimum height, depending on the relative positions of source, barrier and receiver and on the required attenuation spectrum. The main benefits of this approach are that no direct intervention on the components is needed and that fair noise reductions can be obtained at a reasonable cost. The reference document for the construction of barriers for power substations is once again the IEEE 1127-2013 Guide. The flexibility of this solution in a wide range of applications is presented in [14]. Examples of noise barriers designed for the control of noise from transformers can be found in the literature [15]. Traditional noise barriers are not the only way to tackle the problem. For example, Ostiguy et al. [16] recently tested the efficacy of flexible acoustical blankets applied to the case of a $125 \mathrm{kV}$ transformer, showing excellent results. Wang et al. [17] proposed a combination of a traditional barrier with 3D-printed acoustic metamaterial and an active noise control system, obtaining promising results from simulations. Active control is indeed another noise control option that can be used to abate noise from transformers, as reviewed by Zou et al. [18] and by Qiu et al. [19] and as demonstrated by the positive results shown by in-field applications $[17,20,21]$.

The degree of annoyance with continuous audible noise greatly depends upon the relative level of the background ambient noise. The human ear is normally sensitive only to the most dominant among 
several noises. Sources of ambient noise in the community include vehicular or railway traffic, factories, aircraft, animals, and appliances such as attic fans, air conditioners, and lawn mowers. If ambient noise is very low, even a small amount of wind can override the other noise sources and become the dominant ambient noise. For this reason, the generation of broadband masking noise, often in the form of natural sound, is a good way to attenuate the impact of disturbance on the population. This technique has already been successfully applied to mask unwanted noise in public spaces [22], industrial noise [23], and traffic noise [24]. Water has been proved to be particularly effective to improve the soundscape, because associated with positive perceptions [25].

In the literature, the problem of noise from electrical infrastructures is mainly treated in terms of design best practices, which, however, is rarely applicable to old existing equipment. In this case, noise barriers are the preferred solution, but not much information can be found about the strict size and shape constraints that limit their attenuation capability, especially at low frequency. As a result, this measure alone may not be sufficient, but most of literature works focus on a single technique rather than exploring the possibility of combining more of them.

In this work, a case study is presented of a power substation which, due to urban expansion, has gradually been surrounded by closer and closer residential buildings, and must now be evaluated from the viewpoint of potential noise disturbance. The scope of the work is to show how such a complex real problem can be tackled by recalling several techniques normally used in the most diverse acoustic problems, like room acoustics, office noise and soundscaping.

The next section deals with the description of the case at hand, the applied methods and the characterization of the sound source. Section 3 presents and discusses the results of simulations carried out using a pyramid-tracing software, the validation of the model and the application of traditional mitigation actions. Moreover, the application of masking noise techniques is also investigated. Finally, Section 4 draws the conclusions of the study.

\section{Methods}

\subsection{Description of the Case and Noise Control Strategy}

The case study involves a power substation for a railway south of Turin, in North-West Italy. The railway station dates back 1854 and the power substation, which henceforth will be referred to as "RPS", was built in 1961, when the area was rural. Over time, the urban district has gradually expanded north (1960s-1970s and after 2010) and south (2000s) of the area, for which the substation is now very close to the houses. The closest buildings are $60 \mathrm{~m}$ far from the north-east side of the source enveloping surface. The most recent dwellings have been evaluated noise-wise to check and limit the disturbance as much as possible. Among these, a receiver located $130 \mathrm{~m}$ far from the substation at a height of $4 \mathrm{~m}$ above the ground (Figure 1) has been considered.

Given the number of buildings and their short distance from the source, reflections are expected to play an important role in noise propagation. The RPS substation has been revamped in the 1980s and the power of its two transformers increased. The transformers, TR1 and TR2, are 25,000 kVA devices with dimensions $6 \mathrm{~m} \times 4 \mathrm{~m} \times 3.5 \mathrm{~m}$ each, whose acoustic characterization is described in Section 2.2. The vibration of the transformer's core at twice the network frequency and its harmonics is responsible for most of the sound emission. 


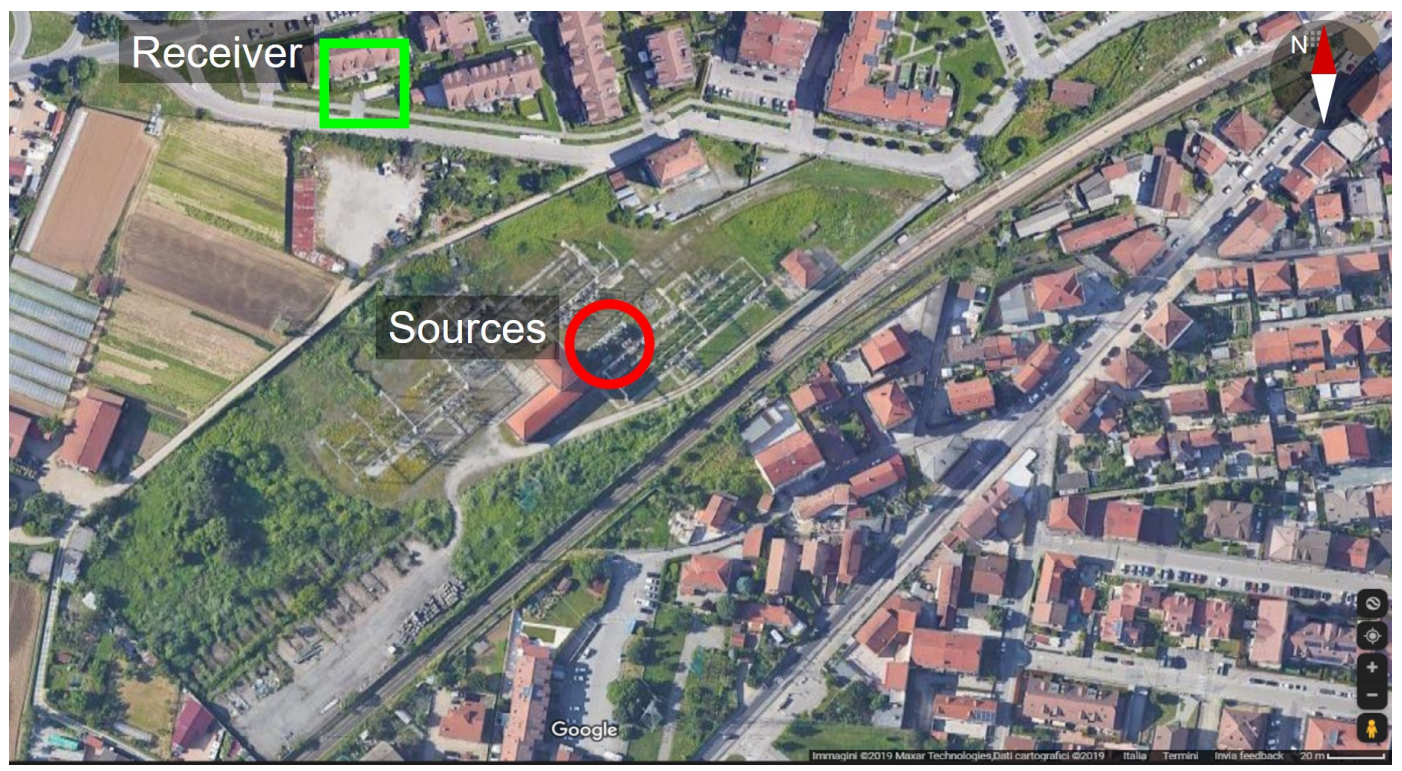

Figure 1. Satellite image of RPS substation. Sources circled in red; receiver in green box. Imagery (C)2019 Maxar Technologies, Map data (C)2019 Google.

Building a noise barrier close to the source is the most common way to mitigate this problem. However, space constraints exist that reduce the practical benefit that can be obtained with this solution: for this reason, noise masking can be exploited as complementary measure. Noise masking consists of immersing the receiver in a pleasant background noise able to conceal the tonal components of the original noise spectrum. Methods to estimate the required masking level are available in the literature see for instance Fastl and Zwicker [26] and Gelfand [27], with an outcome related to psychoacoustics and therefore subjective. In this respect, an auralization process to recreate the designed soundscape and have it evaluated by the potential receivers could be a helpful psychoacoustical tool.

Considering the environment under investigation as a linear time-invariant system, Figure 2, the output signal $y(t)$ is related to the input signal $x(t)$ through the impulse response of the system:

$$
y(t)=(h * x)(t)
$$

where $*$ indicates the convolution product.

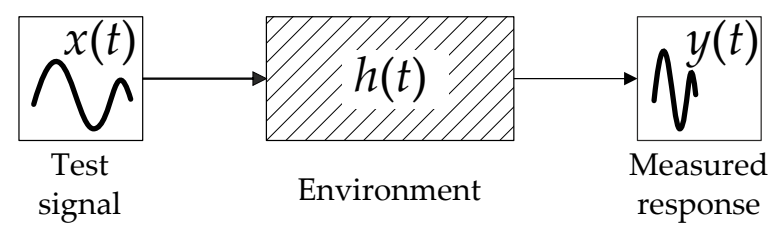

Figure 2. Linear time-invariant system.

The impulse response $h(t)$ can be obtained from the transfer function $H(f)$ through the relationship $H(f)=\mathcal{F}\{h(t)\}$, where $\mathcal{F}$ is Fourier transform and the transfer function is defined between two meaningful source and recording positions. In the present case, $h(t)$ is the impulse response of the environment and $x(t)$ is an anechoic recording of the signal, so that $y(t)$ is the source noise (before or after mitigation) as heard at the receiver's position. Using the impulse response approach allows the obtaining of extra information, such as the time history of the signal as a result of the contributions by reflections, which can be particularly interesting in case of urban environment.

The impulse response of the environment cannot be calculated by the standard "ray-tracing" codes that are conventionally used to evaluate outdoor propagation and that are based on the formulas 
described in ISO 9613-2 standard [28], but it can be rather obtained with the same approach employed with theaters and indoor spaces. The codes developed for room acoustics simulations are primarily made to estimate sound quality parameters such as reverberation time, clarity index, gain and lateral fraction, for which the time history of the sound rays (and, therefore, the impulse response of the room) is necessary. On the other hand, phenomena such as grazing incidence over the absorbing soil and ray curvature due to wind or temperature gradients have a minor impact in indoors simulation and, therefore, room acoustic codes in general do not keep them into account. However, such aspects become relevant outdoors as the distance between the source and the receiver increases and at high frequency [29]. Therefore, when using room acoustics software for noise propagation outdoors, a validation is necessary to consider the results reliable (see discussion in Section 2.4). In this work, ray-tracing software package Ramsete [30] is used to estimate the sound pressure level and the impulse response of the environment surrounding the transformers in the case at hand (distance between source and receiver $130 \mathrm{~m}$, main frequency range of interest below $800 \mathrm{~Hz}$ ). The software requires in input a detailed acoustic model of the source, which must therefore be characterized.

\subsection{Characterization of the Sound Source}

Measurements for the characterization of the sound source have been carried out in two separate sessions. The first experimental campaign has been performed in RPS substation (Figure 1), in order to determine the sound power level of the sources and to collect recordings in prescribed confidence points for validation purpose. Sound power levels have been measured using a sound level meter and the scanning technique described in IEC EN 60076-10 [31]. According to the standard, the sound power level of a source $L_{\mathrm{W}}$ can be determined based on a series of measurements of the sound pressure level (SPL), $L_{\mathrm{p}}$, carried out on a surface enveloping the source, once the possible presence of background noise and reflections is considered:

$$
L_{\mathrm{W}}=\left\langle L_{\mathrm{p}}\right\rangle+10 \log _{10} \frac{S}{S_{0}}
$$

where $\left\langle L_{p}\right\rangle$ is

$$
\left\langle L_{\mathrm{p}}\right\rangle=10 \log _{10}\left(10^{0.1\left\langle L_{\mathrm{p} 0}\right\rangle}-10^{0.1\left\langle L_{\mathrm{bg}}\right\rangle}\right)-K
$$

$K$ represents the correction for the effect of reflections, which can be neglected when the measurements are performed outdoors and the difference between source-on and source-off pressure levels is above $15 \mathrm{~dB}$, as in the present case. $L_{\mathrm{p} 0}$ is the energetic average of the measured sound pressure level, $L_{\mathrm{bg}}$ is the background sound pressure level and $\langle\cdot\rangle$ denotes spatial averaging.

This technique is suitable to characterize the sound power level of large sources since it can uniformly collect energy on the envelope surface, thus it can fairly represent the actual average emission of the device. The two transformers TR1 and TR2 have been evaluated by temporarily switching off either device while the other one was assessed. The enveloping surface is a virtual box whose walls are at $1 \mathrm{~m}$ distance from the transformer's case. A challenging problem is the presence of strong electric field close to the source, which considerably limits the maximum height at which measurements can be carried out safely. This height has been estimated as $3.5 \mathrm{~m}$, above which the recordings get disturbed and the operation can damage the equipment or even be dangerous for the operator. Therefore, it is impossible to measure the top surface of the enveloping box, which is the reason the procedure prescribed by the standard explicitly excludes the top surface from the evaluation, thus accepting that a part of the emitted power is neglected.

The sound level meter is a Larson Davis 831-C with PCB Piezotronics Type 377B02 1/2" microphone and windproof cover. The measured sound power levels are $101 \mathrm{~dB}$ for TR1 and $98 \mathrm{~dB}$ for TR2. The sound pressure level spectrum at $5 \mathrm{~m}$ from the transformer's case and the sound power spectrum are shown in Figure 3. It can be observed that as expected, the main components are in the 100, 200 and $315 \mathrm{~Hz}$ one-third octave bands. 

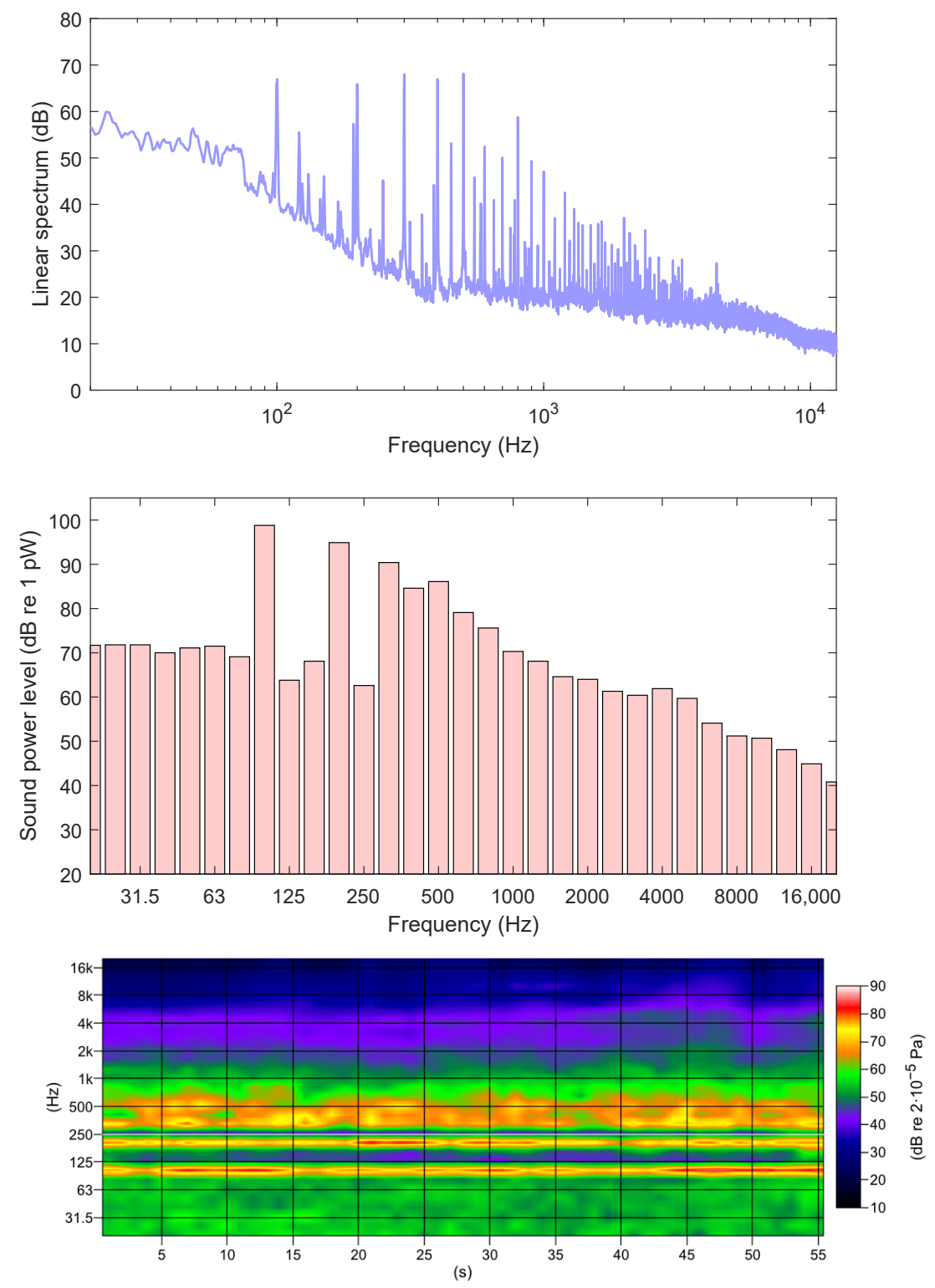

Figure 3. Characteristics of TR1 transformer. From top to bottom: sound pressure level spectrum at $5 \mathrm{~m}$ from the transformer's case; sound power spectrum; spectrogram.

The spectrogram at the bottom of Figure 3 is obtained from scan measurements performed by an operator walking around the perimeter of TR1 at constant speed, so that the time-dependence illustrated in the plot can be viewed as an angle-dependence. In this respect, the spectrogram provides first evidence that noise emission from the source is not uniform and a directivity analysis is required.

The directivity can be found from the directivity factor $D F_{\theta}(f)$, defined for each frequency band $f$ as the ratio between the sound intensity along direction $\theta, I_{\theta}(f)$, and the intensity of an omnidirectional source of the same power input $I_{0}(f)$ at distance $r$ from measurement point:

$$
\begin{gathered}
D F_{\theta}(f)=\frac{I_{\theta}(f)}{I_{0}(f)} \\
I_{0}(f)=\frac{W}{4 \pi r^{2}}
\end{gathered}
$$


The directivity index DI is used instead of the directivity factor:

$$
D I(f)=10 \log _{10}\left(D F_{\theta}(f)\right) .
$$

Directivity measurements have been carried out on a similar single transformer (TR3) located in a different area, to avoid the influence of a second device. The sound pressure level has been sampled on a series of points as illustrated in Figure 4. Several people and considerable equipment were involved (see an example of similar measurement in Figure 5). In particular, 30 measurement positions have been radially distributed around the source at a distance of $10 \mathrm{~m}$ from its center, equally spaced by $12^{\circ}$. Analog noise signals have been recorded with five 1/4" microphones PCB Piezotronics Type 130A23, connected to an Oros OR36 multichannel analyzer. Mounted on level staffs, for each radial position the microphones have recorded the noise along three heights and the average value has been computed. The resulting directivity plots at 100, 200 and $315 \mathrm{~Hz}$ are reported in Figure 6.

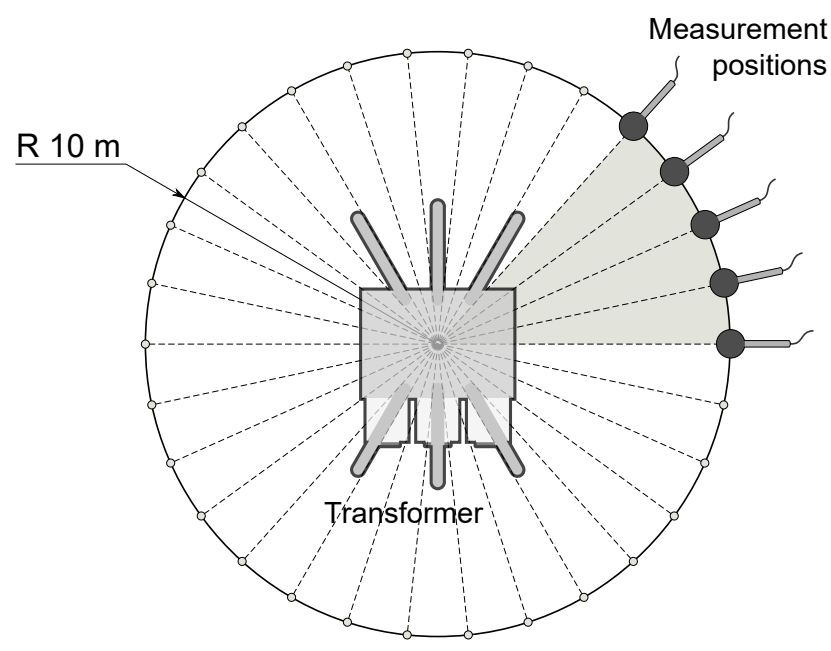

Figure 4. Measurement positions for directivity measurements.

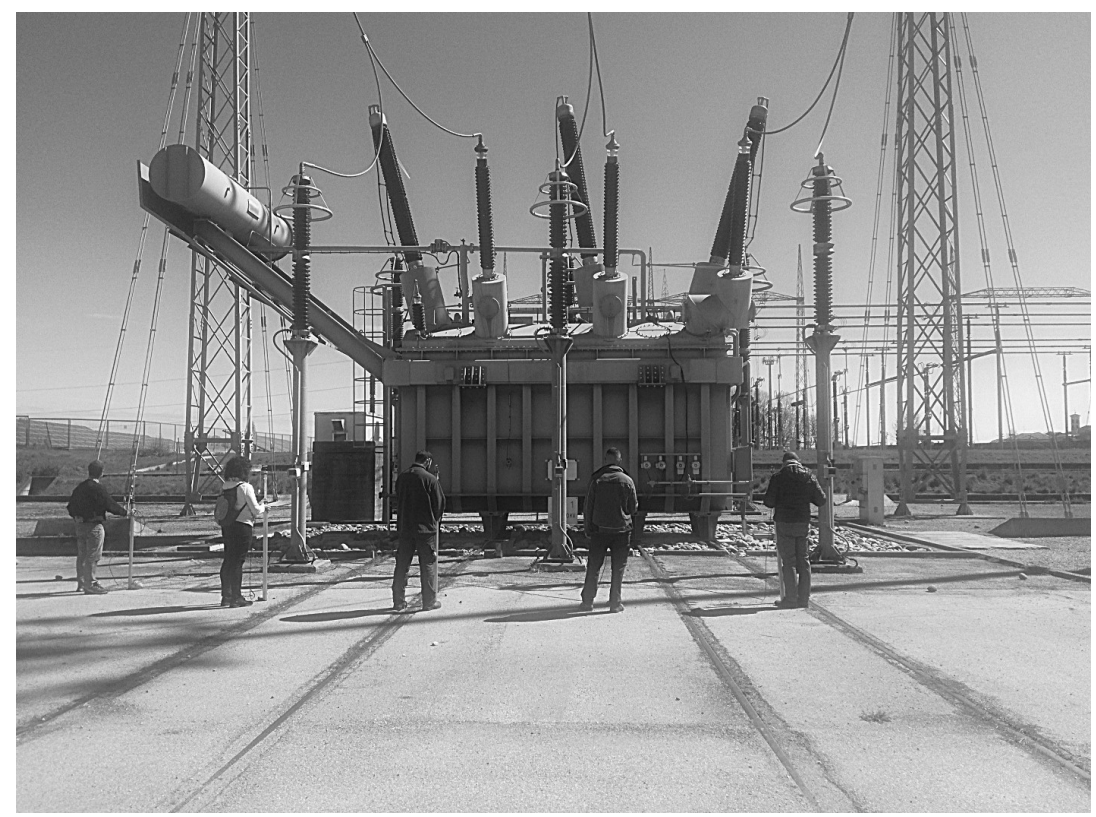

Figure 5. An example of directivity measurement around a transformer. 

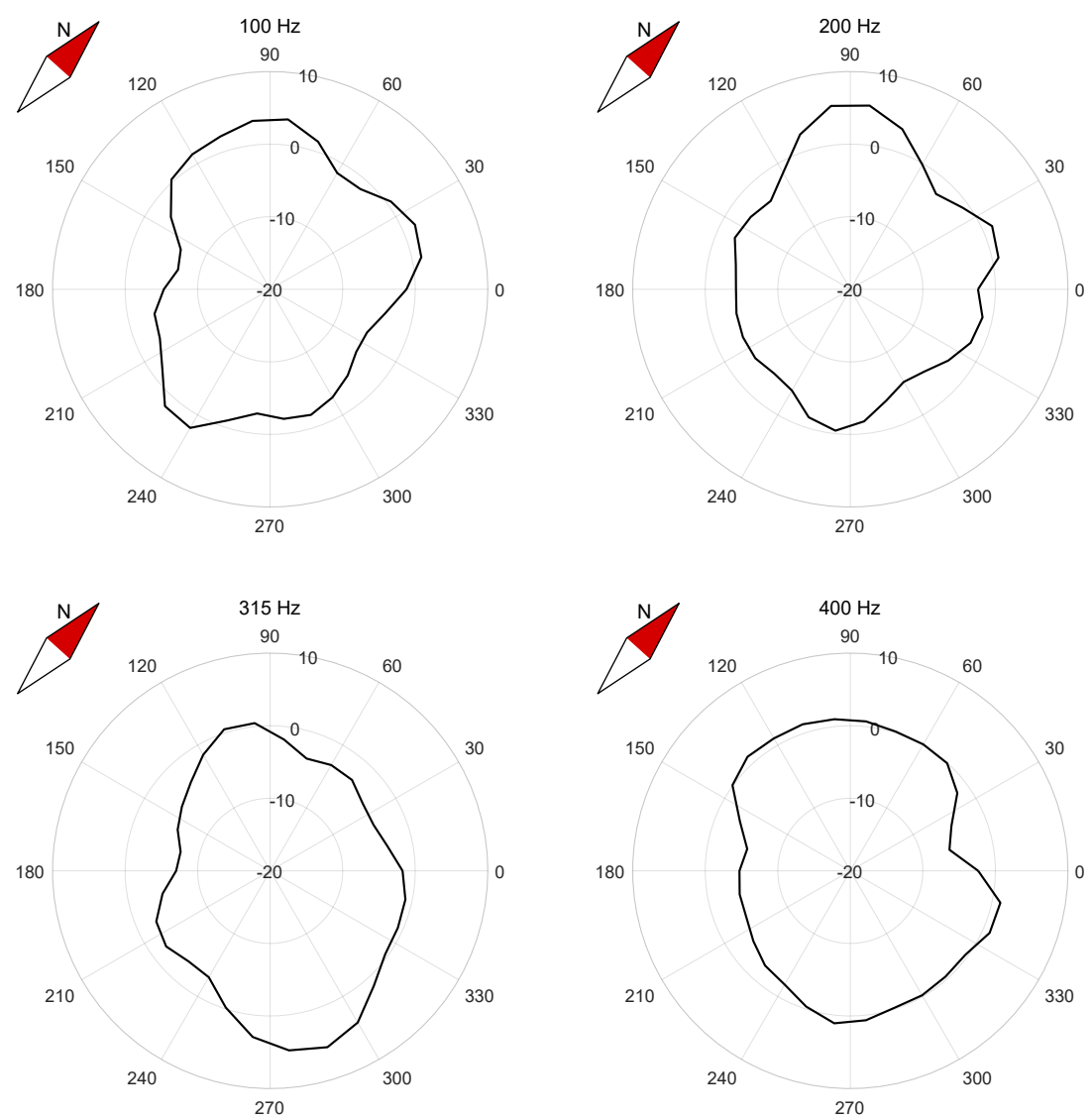

Figure 6. Directivity plots for the three frequencies under investigation (averaged over three heights: $1.5 \mathrm{~m}, 2 \mathrm{~m}$ and $3.1 \mathrm{~m})$.

\subsection{Noise Propagation Modeling}

The geometric and acoustic data have been given as input to Ramsete, a pyramid-tracing software developed by the University of Parma, Italy, for room acoustics. The program can also be used to model noise propagation outdoors for limited distances between source and receiver (see Section 2.1). A visual rendering of the model before importing it in Ramsete is given in Figure 7.

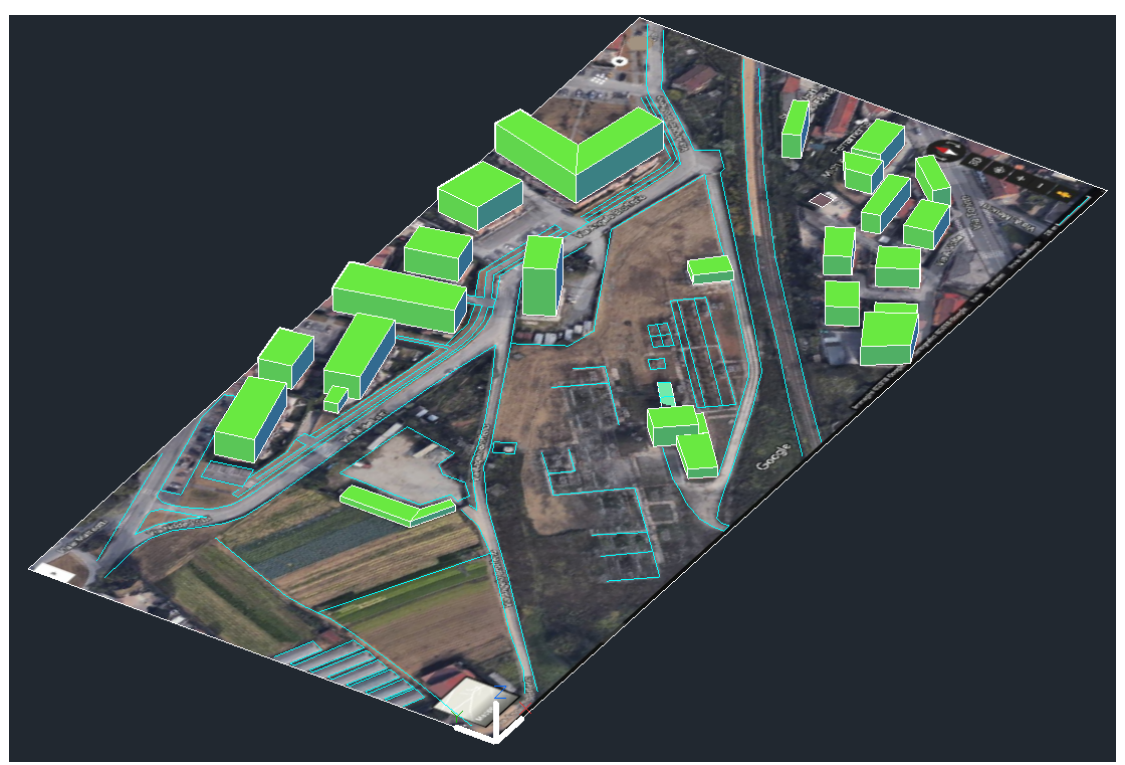

Figure 7. Three-dimensional representation of the model. Imagery (c)2019 Maxar Technologies, Map data (C)2019 Google. 
After importing the model in Ramsete, the source and the receivers have been set. Each source has been defined through the sound power spectrum measured in the first experimental session (TR1/TR2) and the average directivity index obtained from the second session (TR3). As concerns the sound absorption characteristics of the involved materials, the only relevant group of trees is located south-west of RPS substation. Considering the relatively small fraction represented by this green area, its distance from the source, the position of the receiver and the position of the substation technical building, it has been concluded that the trees do not significantly modify the sound propagation characteristics, thus the values in Table 1 have been used. The sound absorption of air is considered by Ramsete through a simplified formula as a function of frequency, distance and relative humidity [29].

Table 1. Sound absorption coefficients for different model elements.

\begin{tabular}{lcccc}
\hline Frequency (Hz) & $\begin{array}{c}\text { Grass } \\
\text { (Ground) }\end{array}$ & $\begin{array}{c}\text { Ballast } \\
\text { (Ground Around the Source) }\end{array}$ & $\begin{array}{c}\text { Asphalt (from [32]) } \\
\text { (Roads) }\end{array}$ & $\begin{array}{c}\text { Plaster (from [32]) } \\
\text { (Façades) }\end{array}$ \\
\hline 31.5 & 0.04 & 0.11 & 0.02 & 0.01 \\
63 & 0.09 & 0.34 & 0.02 & 0.01 \\
125 & 0.12 & 0.58 & 0.02 & 0.01 \\
250 & 0.15 & 0.96 & 0.03 & 0.01 \\
500 & 0.42 & 0.96 & 0.03 & 0.01 \\
1000 & 0.49 & 0.89 & 0.03 & 0.03 \\
2000 & 0.58 & 0.70 & 0.03 & 0.06 \\
4000 & 0.64 & 0.70 & 0.02 & 0.06 \\
8000 & 0.70 & 0.07 & 0.02 & 0.07 \\
16,000 & 0.83 & 0.70 & 0.02 & 0.07 \\
\hline
\end{tabular}

A second simulation is performed to calculate the impulse response of the environment at the receiver for auralization purpose. In this case, the actual noise sources are removed and replaced by a white noise source with the same directivity of the transformer, in order to obtain an ideal function that can be "colored" with the investigated sound through convolution.

\subsection{Preliminary Validation}

The validity of the application of Ramsete to the simulation of outdoor propagation has been verified in a similar case concerning the reduction of noise generated by a transformer (TR4) pertaining to an electrical substation located in a rural area (Figure 8).
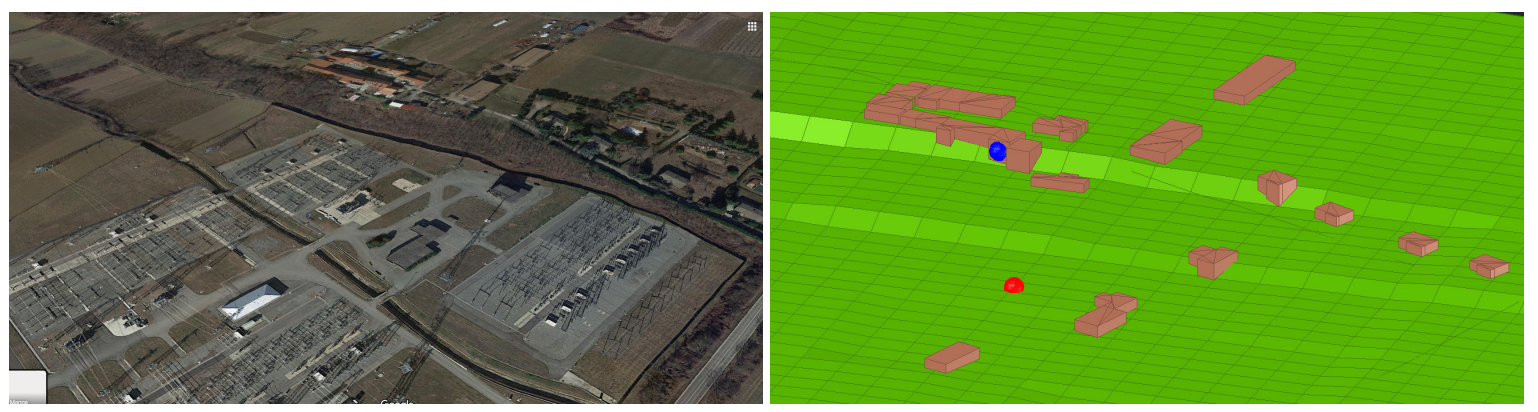

Figure 8. Left: area involved in the simulation for the fully validated case (Imagery (C)2020 Google, Imagery (C)2020 Maxar Technologies, Map data (C)2020 Google). Right: digital terrain model with transformer TR4 indicated in red and the receiver in blue.

Night measurement at the receiver, whose building is zoned in Class III, gave an equivalent SPL of $49.9 \mathrm{~dB}(\mathrm{~A})$ with the presence of a tone at $200 \mathrm{~Hz}$. The Ramsete model returned an equivalent SPL of $49.6 \mathrm{~dB}(\mathrm{~A})$ in the same position and the correct amplitude of the $200 \mathrm{~Hz}$ tonal component. Due to the penalization on the immission level deriving from the presence of the tone, the implementation of a noise control strategy was necessary. A noise barrier was designed respecting the safety constraints 
linked to the electrical equipment: a $5.35 \mathrm{~m}$ high, complexly shaped wall was devised around transformer TR4 and a new simulation with the barrier was run. According to the software calculations, the barrier should have decreased the equivalent SPL at the receiver to $37.7 \mathrm{~dB}(\mathrm{~A})$, with a reduction of the $200 \mathrm{~Hz}$ tonal component by $5 \mathrm{~dB}$ with respect to the original situation.

The noise barrier has been completed in early 2018 (Figure 9) and a final experimental campaign has been performed. The measured equivalent SPL at the receiver was found to be $37.3 \mathrm{~dB}(\mathrm{~A})$ with a reduction of the $200 \mathrm{~Hz}$ tonal component of $5 \mathrm{~dB}$, exactly as predicted by the simulations.

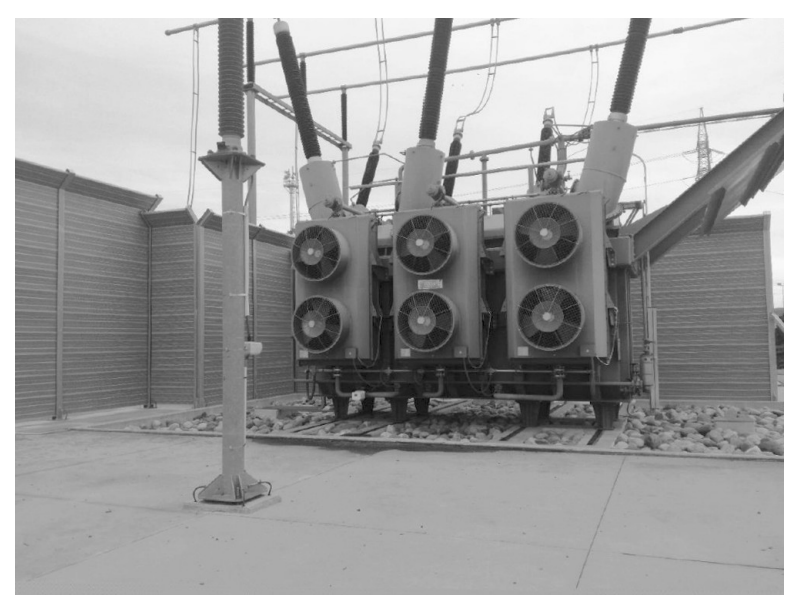

Figure 9. Transformer TR4 surrounded by a noise barrier in the fully validated case.

\section{Results and Discussion}

\subsection{Before Situation}

In this section, RPS substation described in Section 2.1 is considered. Both numerical simulations and experimental results will be shown. After setting up the ray-tracing model as described in Section 2.3, and using the source characteristics as described in Section 2.2, it is possible to compute the sound pressure level distribution in the simulation area on a plane located $4 \mathrm{~m}$ above the ground, i.e., the height of the receiver. The result is shown in Figure 10.
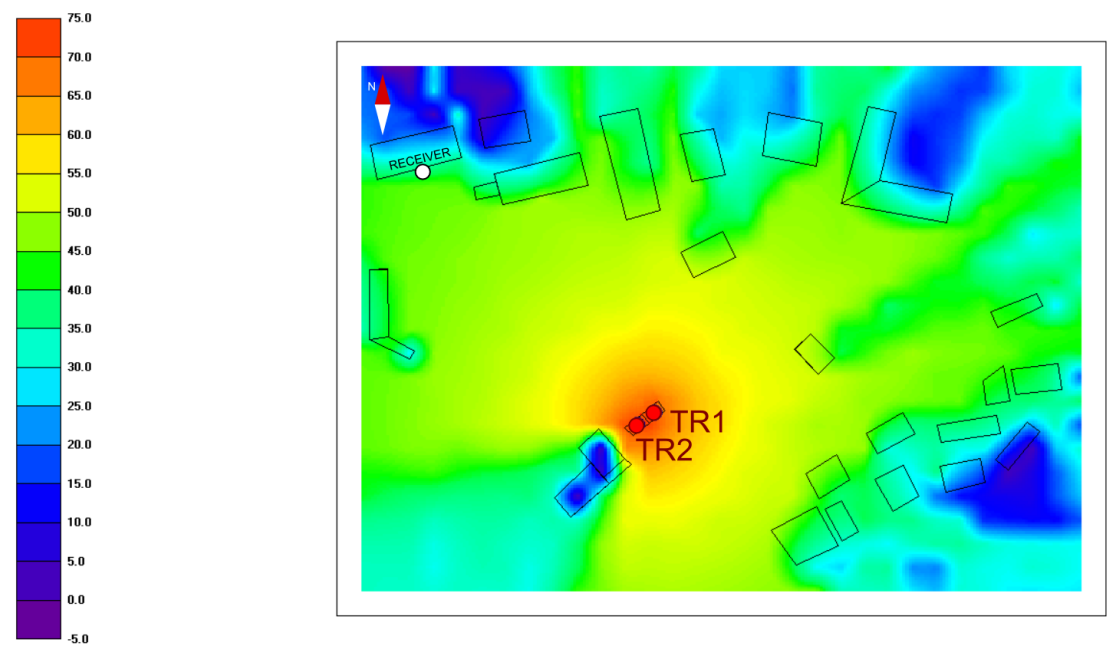

Figure 10. Overall A-weighted SPL distribution in the investigated area as obtained from simulation $4 \mathrm{~m}$ above the ground.

The sound pressure level around the sources is about $75 \mathrm{~dB}(\mathrm{~A})$. Due to the close vicinity of a building, the sound pressure level distribution is not uniform around the source. The presence of 
other buildings causes reflections and shadow zones clearly visible in the map. The SPL at the receiver, located in the north-western part of the investigated area (Figure 1), is between $40 \mathrm{~dB}(\mathrm{~A})$ and $45 \mathrm{~dB}(\mathrm{~A})$ and it is caused by both direct and reflected sound. The Italian legislation (Law 26/10/1995 n. 447 [33]) defines the limit value of emission as the maximum noise that can be emitted by a noise source, measured close to the source itself, and the limit value of immission as the maximum noise that can be introduced by one or more noise sources in the environment, measured close to the receivers. The D.P.C.M. 14/11/1997 [34] sets the limit values of emission and immission for six classes defined according to the intended use. Class I includes particularly sensitive areas where a quiet environment is deemed essential; predominantly residential areas with low population density are zoned in Class II, while mixed-use areas with medium population density, local and connection traffic, commercial activities and offices but no industries belong to Class III. Class IV is characterized by intense human activity and high connection traffic from major roads, railways or harbors. Class V defines mainly industrial areas with low residential population density, whereas Class VI is devoted to exclusively industrial areas with no dwelling. It is worth noting that the legislation requests that a buffer zone is set around roads and railways, and that contiguous areas must belong to contiguous classes (for example, an area zoned in Class III can only be surrounded by Class II and/or Class IV areas). In the presented case, the receiver has been zoned in Class III due to the presence of the railway nearby (zoned in Class IV). This means that the daytime and nighttime immission limits on the measured equivalent sound pressure levels are $60 \mathrm{~dB}(\mathrm{~A})$ and $50 \mathrm{~dB}(\mathrm{~A})$, respectively. The power transformers are working continuously during both time periods. For this reason, it can be assumed that the most critical situation is reached during the night period, when the class limit is lower.

The measurement of the background noise during the nighttime, at the balcony located on the façade of the house where the receiver has been positioned ( $4 \mathrm{~m}$ above the ground), gave an equivalent sound pressure level of $46 \mathrm{~dB}(\mathrm{~A})$. Figure 11 shows the spectrum of the minimum values measured for each band, which is the reference spectrum type for the detection of tones according to Italian legislation [35]. It can be observed that there are no tonal components in the background noise spectrum and the background noise perception is mainly related to the traffic noise contribution from a close free-way, represented by a broadband noise around the $630 \mathrm{~Hz}-1 \mathrm{kHz}$ frequency range.

The measurements carried out on the balcony of the receiver's house with the two transformers turned on gave an equivalent sound pressure level of $47.4 \mathrm{~dB}(\mathrm{~A})$. This value also includes the background noise, while the model only provides the effect of the sources. Therefore, the two values to compare are the SPL measured at the receiver purged of the background noise, and the simulated SPL at the receiver. The sound pressure level caused by the transformers alone is $47.4 \ominus 46=41.8 \mathrm{~dB}(\mathrm{~A})$, with $\ominus$ indicating energetic subtraction. Since the model gives a sound pressure level due to the two power transformers and without any barrier equal to $42.9 \mathrm{~dB}(\mathrm{~A})$, it can be considered validated, with a difference of $1.1 \mathrm{~dB}$ with respect to the measured value. 


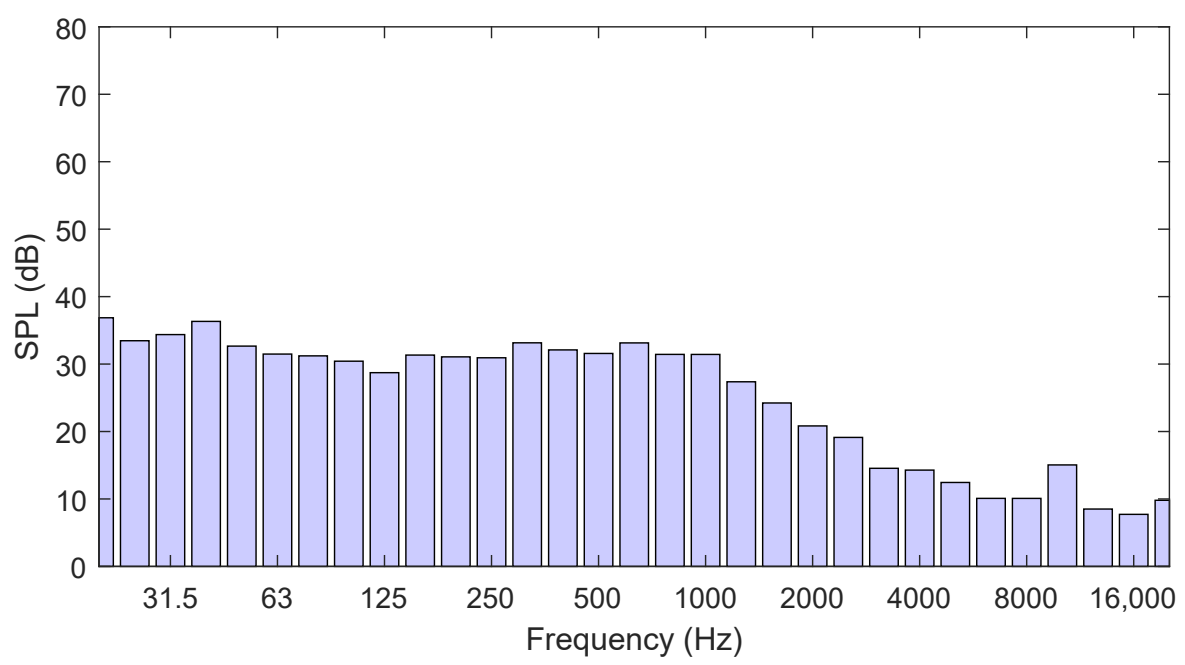

Figure 11. Spectrum of the minimum values for background noise measured at the façade of the receiver building (first floor).

The analysis of the measured results obtained with the power transformers turned on highlights two tonal components in $315 \mathrm{~Hz}$ and $400 \mathrm{~Hz}$ frequency bands (spectrum of the minimum values in Figure 12). Italian legislation (Ministerial Decree 16/03/1998 [35]) prescribes that a penalization of $3 \mathrm{~dB}$ is added to the measured sound pressure level in this case. As a result, the overall immission level encompassing background noise and penalization is $50.4 \mathrm{~dB}(\mathrm{~A})$, i.e., above or very close to the law limit. A mitigation action seems therefore appropriate.

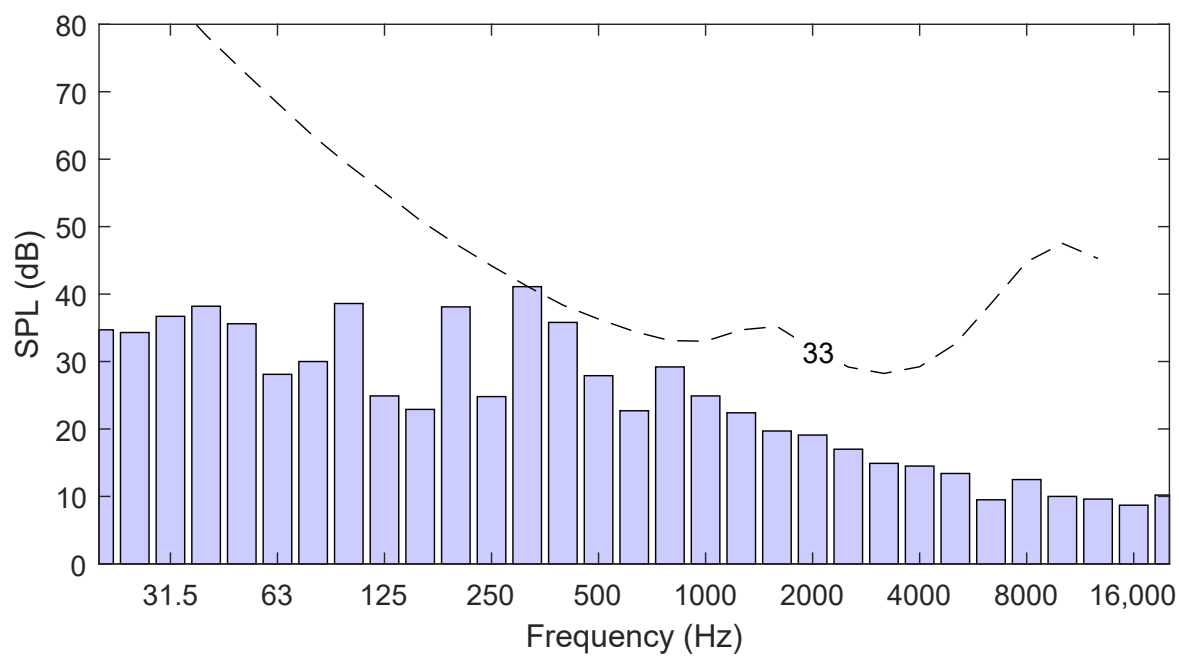

Figure 12. Spectrum of the minimum values for noise measured with the sources turned on at the façade of the receiver building (first floor). Dashed line: 33 phon equal loudness contour.

It is worth remarking that replacing the transformer with less noisy equipment is an expensive and burdensome solution, which in general is exploited in case of extremely severe disturbance when no other solution is available. In the present case, other options exist to solve the problem without changing the components.

To better understand the characteristics of the disturbing tones, the impulse response generated by the software between the source and the receiver can be used. In particular, the narrow band spectrum at the receiver can be reconstructed by convolving the normalized impulse response (Figure 13) with the signal of the noise emitted by the power transformer, $s(t)$, the latter being a WAV file recorded 
during the sound power level measurements in a representative position along the direction towards the receiver:

$$
(h * s)(t)=\int_{-\infty}^{+\infty} h(\tau) s(t-\tau) \mathrm{d} \tau .
$$

The spectrum $L_{\mathrm{p}, 1 / 3, \text { norm }}$ is derived by applying the Fourier transform to the result of this

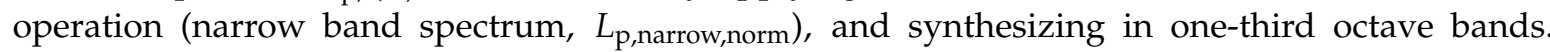
The noise signal obtained convolving the impulse response with the recorded signal must be scaled to emulate the sound perception at the receiver. For this reason, as a first approximation, the calculated spectrum is shifted so that it gives the same overall A-weighted SPL at the receiver as the value computed by the software in the simulation, $L_{\mathrm{p}, \mathrm{A}, \text { tot }}$ :

$$
L_{\mathrm{p}, 1 / 3}=L_{\mathrm{p}, 1 / 3, \text { norm }}+\left[L_{\mathrm{p}, \mathrm{A}, \text { tot }}-10 \log _{10}\left(\sum 10^{\left(L_{\mathrm{p}, 1 / 3, \text { norm }}+A\right) / 10}\right)\right],
$$

where $A$ is the weighting in decibels defined in IEC 61672-1 standard [36]. In this way, the impulse response can be used to evaluate several potentially disturbed points, even when they are not easily accessible for in-field measurements.

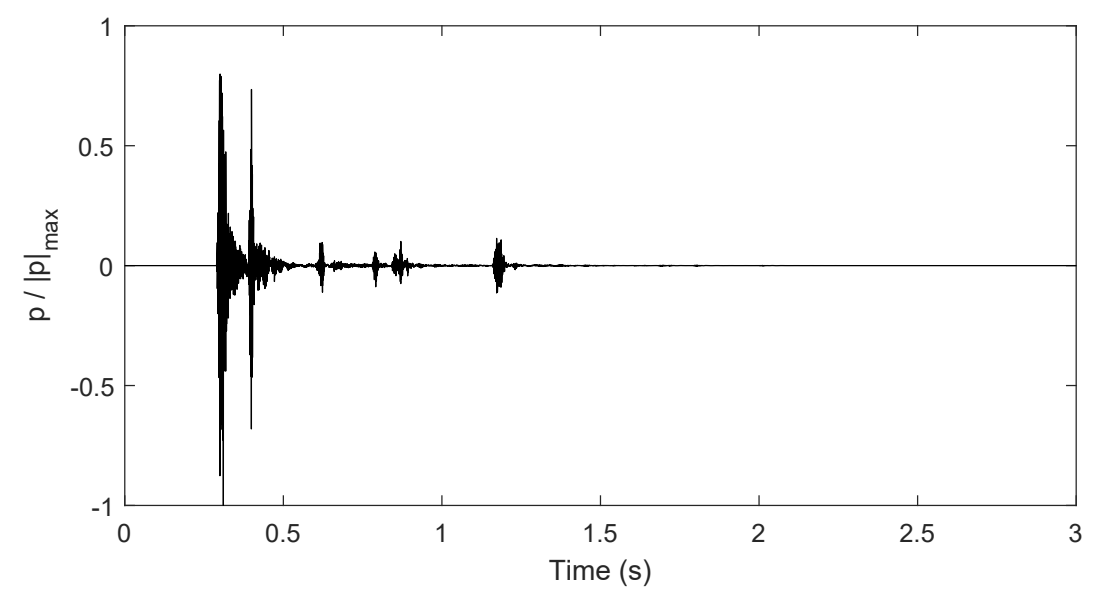

Figure 13. Impulse response computed at the receiver without mitigation measures.

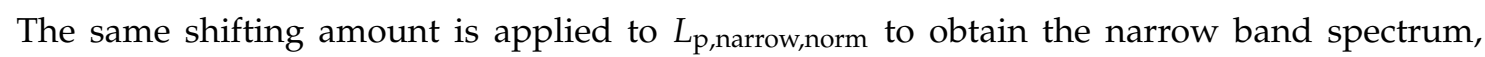
$L_{\mathrm{p} \text {,narrow. }}$ In Figure 14, $L_{\mathrm{p} \text {,narrow }}$ is compared with the equal loudness curve intersecting the highest spectrum peaks, showing which frequency components most contribute to the loudness perception at the receiver. The main contributions are related to the $300 \mathrm{~Hz}, 400 \mathrm{~Hz}, 800 \mathrm{~Hz}$ and $900 \mathrm{~Hz}$ components. It is worth noting that a noise barrier's efficiency is proportional to frequency: the higher the frequency, the stronger the attenuation. Therefore, if this solution is chosen as a mitigation action, further low-frequency attenuation measures are likely to be necessary to control the lowest frequency contributions: for example, as discussed in the following, the addition of low-frequency sound-absorbing material to the barrier and the increase of its height and extension are possible ways to improve the attenuation of the low-frequency components. 


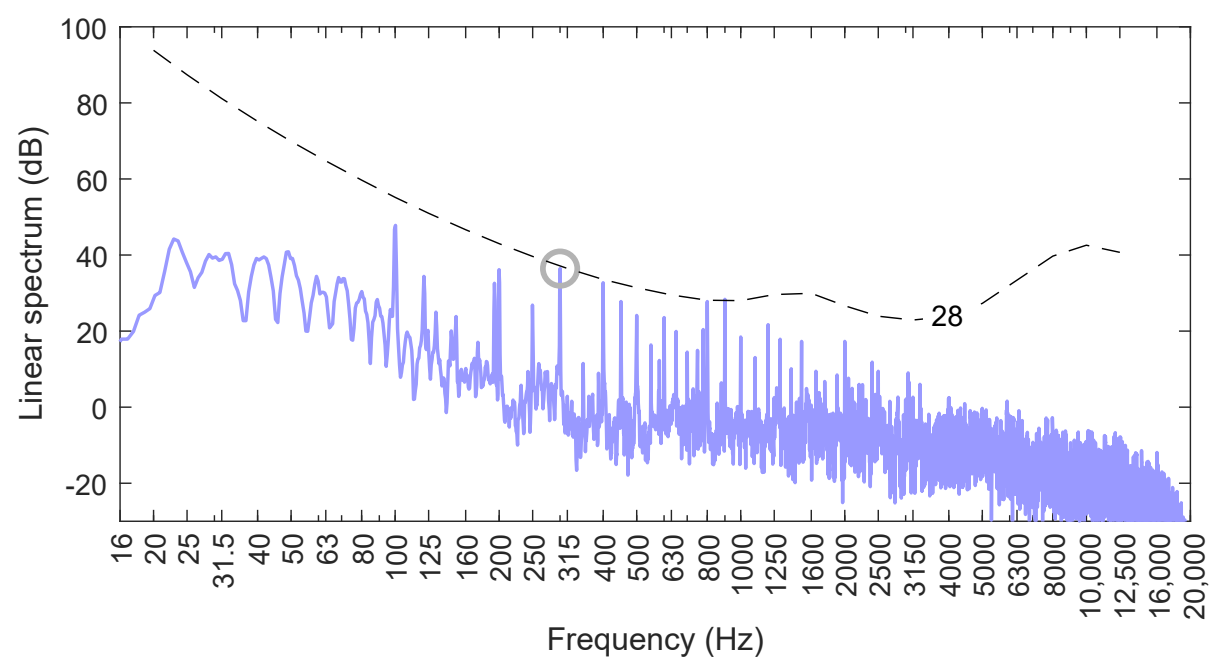

Figure 14. Comparison between the narrow band sound pressure spectrum and the equal loudness contour intersecting the highest frequency component around $300 \mathrm{~Hz}$.

\subsection{Noise Barrier}

A traditional mitigation action is to build a sound barrier with appropriate dimensions, taking into account the safety size and position constraints given by the presence of the HV conductors. Ramsete computes the intensity diffracted by a barrier, $I_{\text {diff }}$, with the well-known formula of Kurze and Anderson [37]

$$
I_{\text {diff }}=I \times \frac{\tanh (\sqrt{2 \pi|N|}}{\sqrt{10} \times \tanh (\sqrt{2 \pi|N|}}
$$

where

$$
N=\frac{2 \delta f}{c_{0}},
$$

and $I$ is the direct intensity component without barrier, $N$ is the Fresnel number, $\delta$ is the difference between diffracted and direct paths, $f$ is the frequency and $c_{0}$ is the speed of sound in air.

After accurate analysis of the layout, it has been concluded that the maximum height and shortest distance from TR1 and TR2 transformers' cases ensuring safe operations are $5.5 \mathrm{~m}$ and $2.1 \mathrm{~m}$, respectively. A new simulation has been performed with a $24 \mathrm{~m}$ long barrier that follows these indications. The material chosen for the barrier are commercial concrete blocks featuring resonators [38], whose sound absorption coefficient as a function of frequency is given in Figure 15.

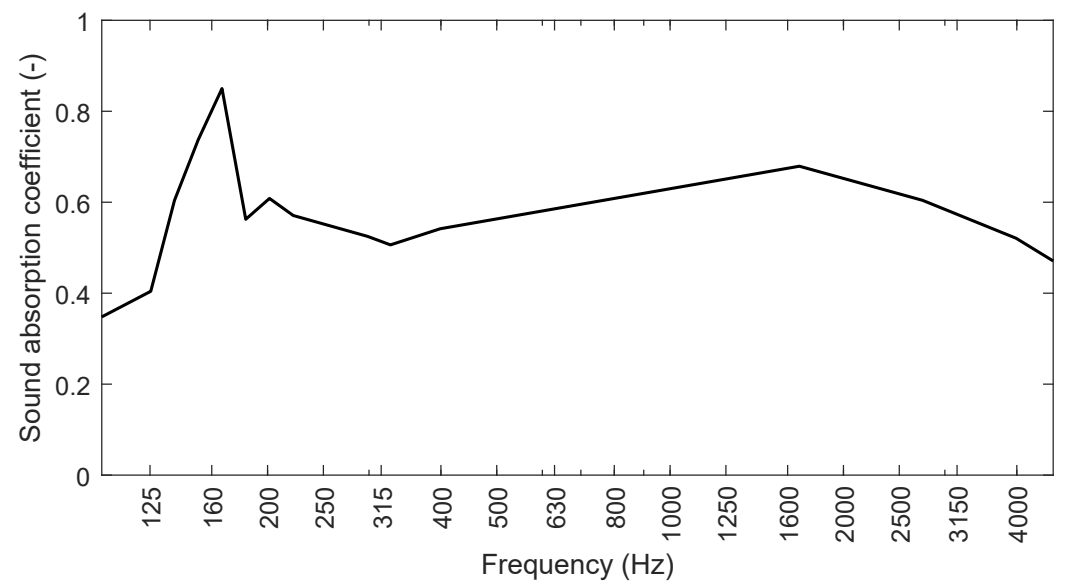

Figure 15. Sound absorption coefficient of the bricks chosen for the barrier (from [38]). 
The impulse response computed at the receiver by the simulation software is shown in Figure 16.

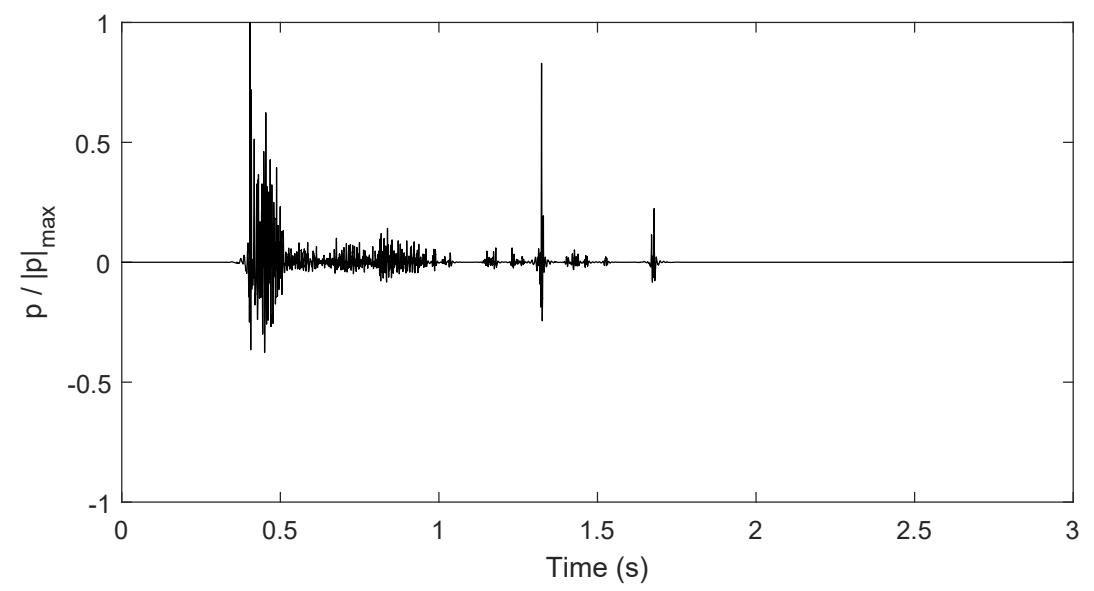

Figure 16. Impulse response at the receiver with a $24 \mathrm{~m}$ long, $5.5 \mathrm{~m}$ high straight barrier placed $2.1 \mathrm{~m}$ far from the transformers.

Comparing the normalized impulse response calculated with the barrier, Figure 16, with the one in Figure 13, it can be observed that the first peak is now delayed since the sound must overcome the barrier to reach the receiver. The wall diffracts and scatters part of the early components, creating a broader profile. On the other hand, it redirects the energy intensifying some of the late reflections (peak at $1.3 \mathrm{~s}$ ). The sound pressure level at the receiver in this case is $32.8 \mathrm{~dB}(\mathrm{~A}), 10.1 \mathrm{~dB}$ less intense than the sound pressure level without barrier, but the sound component reflected from the buildings located south of the sources towards the receiver can still be reduced by improving the shape of the barrier. Based on these considerations, it is convenient to introduce two lateral baffles with a height of $5 \mathrm{~m}$ and a length of $5 \mathrm{~m}$, orthogonal to the main wall as illustrated in Figure 17. The normalized impulse response computed by Ramsete in this situation is shown in Figure 18. The effect of the lateral diffraction is less evident and the peak at $1.3 \mathrm{~s}$ which was visible in Figure 16 is strongly reduced. The sound pressure level computed at the receiver is $28.4 \mathrm{~dB}(\mathrm{~A}), 4.4 \mathrm{~dB}$ below the value obtained for the simple barrier without extensions, yielding a total reduction of $10.1+4.4=14.5 \mathrm{~dB}$ in comparison with the situation without barrier.
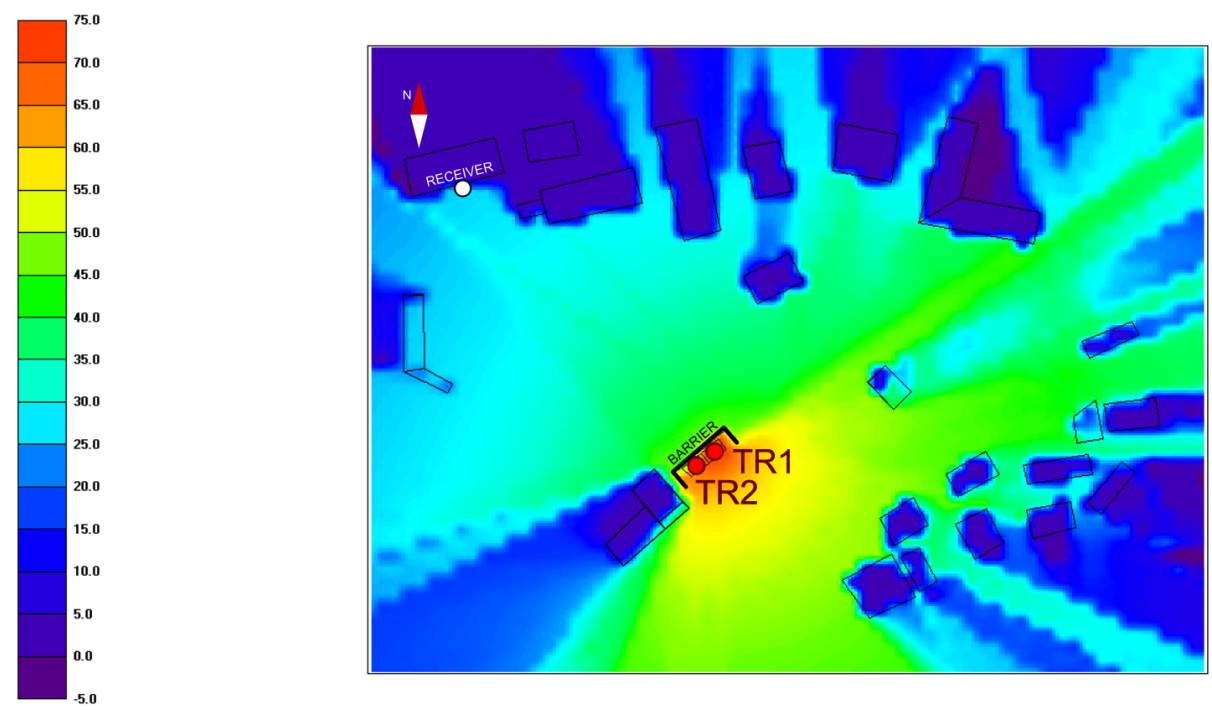

Figure 17. Predicted overall A-weighted SPL distribution in the investigated area, $4 \mathrm{~m}$ above the ground, after the installation of the baffled barrier. 


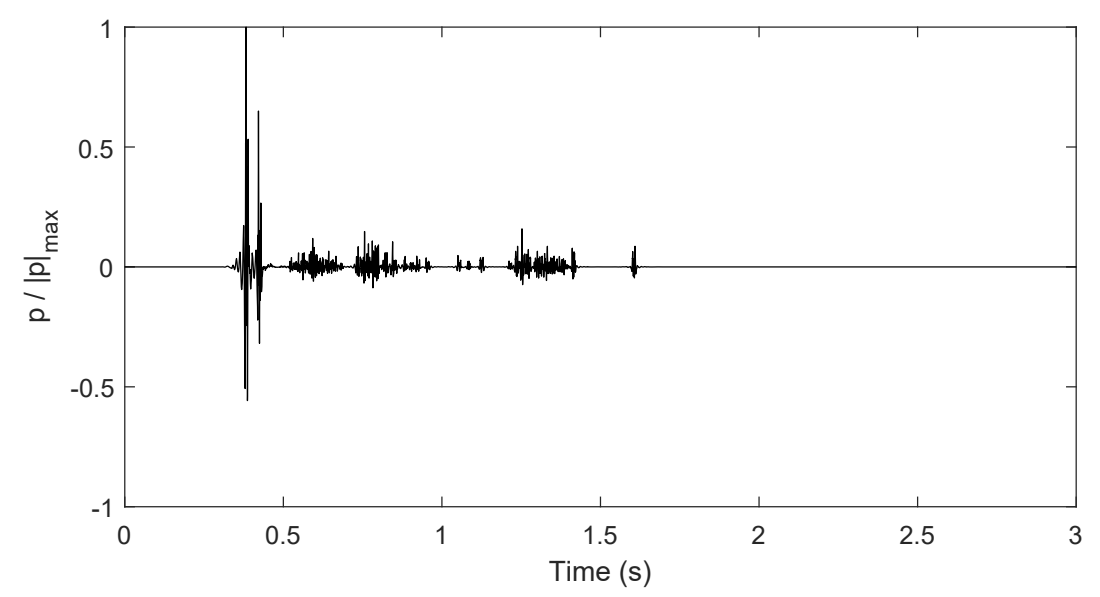

Figure 18. Impulse response in case of barrier with lateral baffles.

Figure 17 shows the sound pressure level distribution at a height of $1.7 \mathrm{~m}$ from the ground. From a comparison between Figure 10 and Figure 17, the mitigation effect of the barrier on the SPL distribution is evident. The addition of more barrier elements south of the sources could further reduce the noise disturbance, but this would create some problems in terms of visibility (the equipment must be "visible for observation" [13]) and maintenance (the south edge is the only one free from obstacles with the proposed solution, thus it would represent the preferred access way for operations on the transformers).

\subsection{Noise Masking}

The narrow band spectrum at the balcony of the receiver's house, predicted by convolving the new impulse response at the receiver and the source noise, is given in Figure 19. It can be observed that despite the presence of the barrier, the $300 \mathrm{~Hz}$ component appears to be well audible since it crosses the 19 phon equal loudness contour. The height of the barrier cannot be further increased for safety reasons, thus other classes of actions must be undertaken.

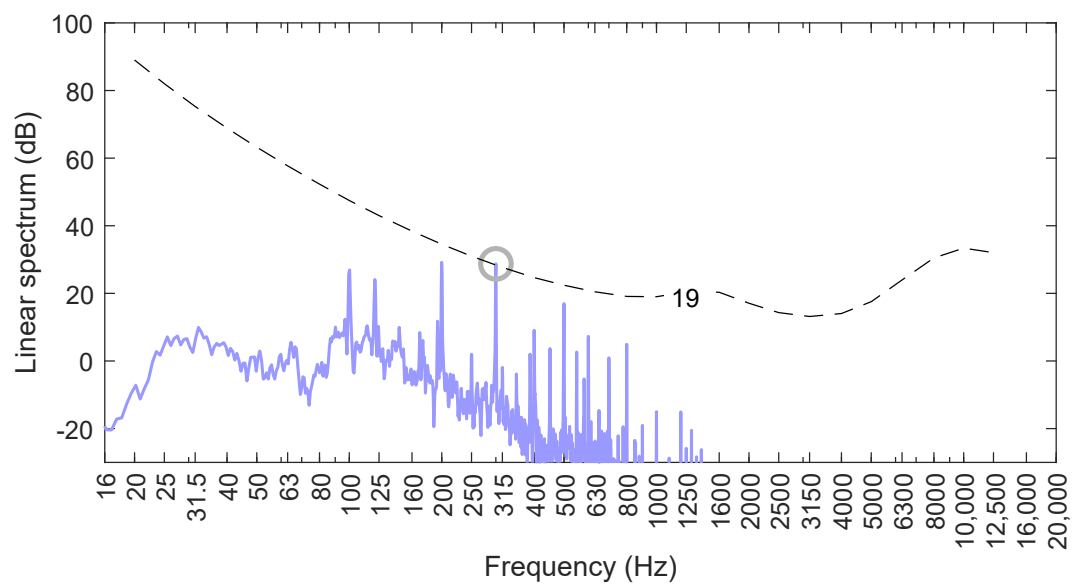

Figure 19. Predicted narrow band sound pressure spectrum at the receiver after the installation of the baffled barrier.

Broadband signals have been used to improve room acoustic quality since the late 1970s. It is possible to conceal a tonal component within a broadband noise overlapping it, to avoid its clear perception by the human ear [27]. In the case at hand, the residual tonal component after the installation of the barrier features an SPL of $28.7 \mathrm{~dB}$ at a frequency of $300 \mathrm{~Hz}$. 
The use of white noise as a masker signal is reviewed by Gelfand [27]. When a second sound is added to an existing one, the detection threshold of the latter increases. The shift between the threshold in quiet and the masked threshold is called "masking". The estimation of the masking effect is based on the masked threshold contours first introduced by Hawkins and Stevens in 1950 [39]. These curves show the masked thresholds produced at each frequency by a white noise at various spectrum levels. In Figure 20 the residual disturbance at $300 \mathrm{~Hz}$ is slightly above the threshold in quiet, thus a masking action could be convenient. If a white noise with $10 \mathrm{~dB}$ spectrum level is chosen, one can estimate the perception difference between the tone and the masking noise by the comparison between two equal loudness curves: with reference to Figure 20, the highest curve touching the tone to be masked (19 phon), and the highest curve touching the masking noise (24 phon), leading to a difference of $5 \mathrm{~dB}$. It is worth remarking the white noise spectrum level must be chosen so that the "sound blanket" is not more annoying than the masked disturbance. The overall A-weighted SPL introduced by the $10 \mathrm{~dB}$ spectrum level signal is equal to $30 \mathrm{~dB}(\mathrm{~A})$, which is $16 \mathrm{~dB}$ below the background noise and, therefore, can be considered negligible.

The background noise detected in the area may be sufficient to mask the disturbance during the daytime, but, coming from vehicle traffic, its masking effect is likely to disappear at night. In this case, the introduction of a broadband signal can be seen as an artificial background noise that ideally could be turned on only at night, thus gradually replacing the daytime traffic noise. A practical implementation of this technique can be achieved either with distributed loudspeaker systems, to be installed in the premises of the disturbed dwelling, or with soundscaping approaches. For example, the spectrum of a water fountain [40] seems particularly suitable to replace the traffic noise, as the energy content of the two signals is very similar in the high frequency range (Figure 21).

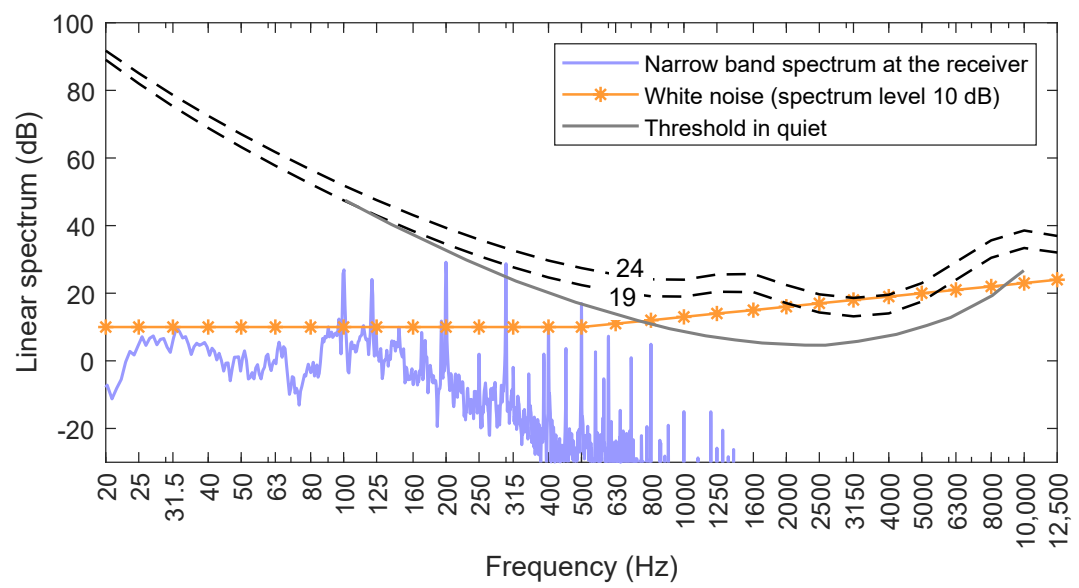

Figure 20. Masking of the tonal component using a white noise. Dashed lines: equal loudness contours at 19 phon and 24 phon. Threshold in quiet adapted from [27]. 


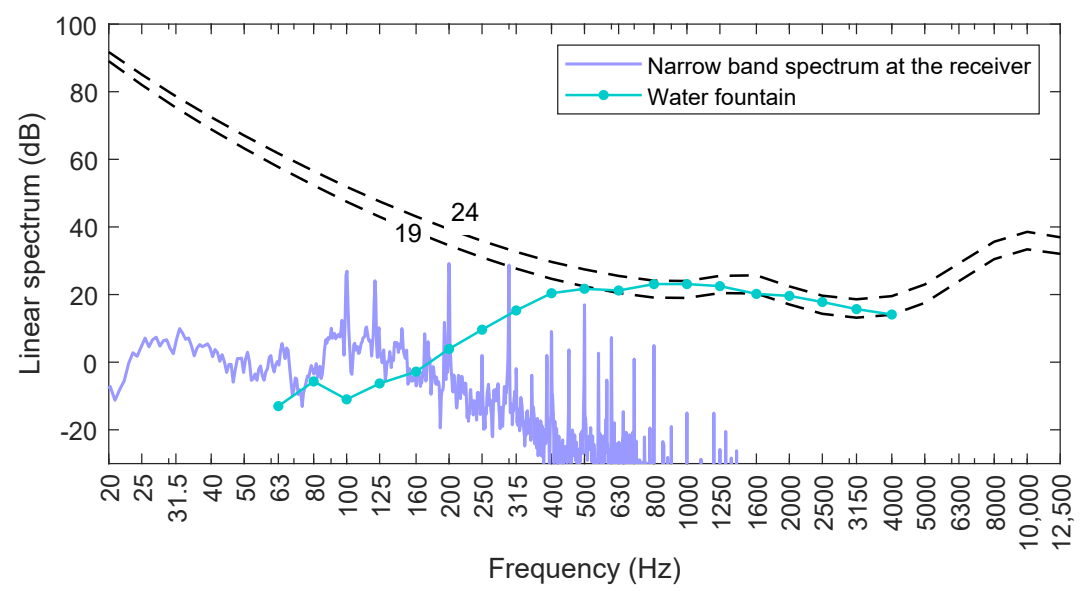

Figure 21. Masking the tonal component using a water fountain noise (shifted spectrum from [40]). Dashed lines: equal loudness contours at 19 phon and 24 phon.

It is worth noting that the introduction of intentional noises should be evaluated from a psychoacoustical perspective. In this respect, the possibility to virtually reproduce the sound signal at the receiver in different scenarios is an interesting possibility that the impulse response reconstruction offers.

\section{Conclusions}

Noise from electrical substations has some peculiarities that make it difficult to develop simple control strategies. In particular, low-frequency disturbances and safety constraints are an issue. Barriers are the most convenient tool to control this kind of noise because they are a good compromise between effectiveness and economic sustainability. Thoroughly characterizing the sound sources, simulating the outdoor sound propagation and calculating the impulse response of the environment, more information can be retrieved, for example on how to improve the barrier shape to attenuate reflections or to predict the impact of the mitigation measures on the receiver. Noise masking with broadband noise is a potential way to integrate the benefit of the barrier when the human-related noise is not sufficient to conceal the residual disturbance. Possible future developments include the optimization of the barrier geometrical characteristics (for instance, based on the definition of a "cost function") and the use of auralization for subjective evaluations of both the effect of noise barriers and the reactions to the introduction of intentional masking noises.

Author Contributions: E.A.P. conceptualized the study, performed the measurements and the simulations and wrote the original draft of the paper. N.B.R. supervised the work, led the formal analysis and revised the manuscript. All authors have read and agreed to the published version of the manuscript.

Funding: This research received no external funding.

Conflicts of Interest: The authors declare no conflict of interest.

\section{References}

1. Pellerin-Carlin, T.; Vinois, J.A.; Rubio, E.; Fernandes, S. Making the Energy Transition A European Success. Tackling the Democratic, Innovation, Financing and Social Challengers of the Energy Union; Technical Report 114; Jacques Delors Institute: Paris, France, 2017.

2. Buck, M.; Graf, A.; Graichen, P. European Energy Transition 2030: The Big Picture. In Ten Priorities for the Next European Commission to Meet the Eu'S 2030 Targets and Accelerate towards 2050; Technical Report; Agora Energiewende: Berlin, Germany, 2019.

3. European Network of Transmission System Operators for Electricity, ENTSO-E. Ten-Year Network Development Plan 2010-2020; Technical Report; European Network of Transmission System Operators for Electricity, ENTSO-E: Brussels, Belgium, 2010. 
4. European Network of Transmission System Operators for Electricity, ENTSO-E. TYNDP 2018 Executive Report. Connecting Europe: Electricity; Technical Report; European Network of Transmission System Operators for Electricity, ENTSO-E: Brussels, Belgium, 2018.

5. Ghaffarpour, R.; Jannati Oskuee, M.; Ranjbar, A. Resilience-oriented distribution network optimal planning to improve the continuity of power supply. Int. J. Amb. Energy 2018. [CrossRef]

6. United Nations. World Urbanization Prospects: The 2018 Revision. In Key Facts; Technical Report; United Nations: New York, NY, USA, 2018.

7. Buchholz, B.M.; Styczynski, Z. Modern Technologies and the Smart Grid Challenges in Transmission Networks. In Smart Grids_Fundamentals and Technologies in Electricity Networks; Buchholz, B.M., Styczynski, Z., Eds.; Springer: Berlin/Heidelberg, Germany, 2014; pp. 61-119. [CrossRef]

8. McDonald, J.D. Electric Power Substations Engineering, 3rd ed.; CRC Press: Boca Raton, FL, USA, 2012.

9. Sanders, H.; Van Waes, J.; Van De Rijt, P.; Sibbel, H.; Wassens, M.; Megens, E. Added value of integrated substations in improving social acceptance of power system infrastructure. In Proceedings of the 44th International Conference on Large High Voltage Electric Systems 2012, Paris, France, 26-31 August 2012.

10. Piana, E.; Bignucolo, F.; Donini, A.; Spezie, R. Maintenance of a high-voltage overhead transmission line: Sustainability and noise impact assessment. Sustainability 2018, 10, 491. [CrossRef]

11. Donini, A.; Spezie, R.; Cortina, R.; Piana, E.; Turri, R. Accurate prediction of the corona noise produced by overhead transmission lines. In AEIT 2016-International Annual Conference: Sustainable Development in the Mediterranean Area, Energy and ICT Networks of the Future; Institute of Electrical and Electronics Engineers Inc.: Naples, Italy, 2016; p. 7892760. [CrossRef]

12. Danesi, G.; Giorgi, A. Considerazioni sul Silenziamento dei Trasformatori delle Stazioni di Interconnessione (Notes on Reducing the Noise in EHV Transforming Substations). Elettrotecnica 1975, 62, 951-956. (In Italian)

13. Institute of Electrical and Electronic Engineers. IEEE 1127-2013-IEEE Guide for the Design, Construction, and Operation of Electric Power Substations for Community Acceptance and Environmental Compatibility; Institute of Electrical and Electronics Engineers: Piscataway, NJ, USA, 2013.

14. Tupov, V.; Semin, S.; Tupov, B.; Taratornin, A.; Rozanov, D. Noise barriers for power-plant equipment. Power Technol. Eng. 2017, 50, 649-652. [CrossRef]

15. Belderrain, M.; Montemurro, W. A new solution of environmental noise control of a transforming station. In Proceedings of the 41st International Congress and Exposition on Noise Control Engineering 2012, INTER-NOISE 2012, New York, NY, USA, 19-22 August 2012; Volume 9, pp. 7247-7255.

16. Ostiguy, P.C.; Pearson, M.; L’Espérance, A.; Gérard, A.; Gosselin, F. Transformer noise reduction using acoustical blankets installed with magnetic mounting bracket. In Proceedings of the 47th International Congress and Exposition on Noise Control Engineering: Impact of Noise Control Engineering, INTER-NOISE 2018, Chicago, IL, USA, 26-29 August 2018; pp. 5567-5576.

17. Ying, L.; Wang, J.; Liu, Q.; Wang, D. Application study of adaptive tracking algorithm in active noise control system of transformer. Appl. Sci. 2019, 9, 2693. [CrossRef]

18. Zou, H.; Tao, J.; Qiu, X. Present status and future development for active control of transformer noise. In Proceedings of the $46^{\text {th }}$ International Congress and Exposition on Noise Control Engineering: Taming Noise and Moving Quiet, INTER-NOISE 2017, Hong Kong, China, 27-30 August 2017; pp. 3607-3613.

19. Qiu, X.; Zhou, H. Recent progress in research on virtual sound barriers. In Proceedings of the 2 nd Australasian Acoustical Societies Conference, ACOUSTICS 2016, Brisbane, Australia, 9-11 November 2016; Volume 1, pp. 244-253.

20. Hu, S.; Chen, S.; Zou, H.; Li, T. Research on the application of active sound barriers for the transformer noise abatement. In Proceedings of the MATEC Web of Conferences, 2016 International Conference on Electronic, Information and Computer Engineering, ICEICE 2016, Hong Kong, China, 26-27 April 2016; Volume 44. [CrossRef]

21. Borchi, F.; Carfagni, M.; Martelli, L.; Turchi, A.; Argenti, F. Design and experimental tests of active control barriers for low-frequency stationary noise reduction in urban outdoor environment. Appl. Acoust. 2016, 114, 125-135. [CrossRef]

22. Nilsson, M.; Alvarsson, J.; Rådsten-Ekman, M.; Bolin, K. Auditory masking of wanted and unwanted sounds in a city park. Noise Control Eng. J. 2010, 58, 524-531. [CrossRef]

23. Cai, J.; Liu, J.; Yu, N.; Liu, B. Effect of water sound masking on perception of the industrial noise. Appl. Acoust. 2019, 150, 307-312. [CrossRef] 
24. Coensel, B.; Vanwetswinkel, S.; Botteldooren, D. Effects of natural sounds on the perception of road traffic noise. J. Acoust. Soc. Am. 2011, 129, EL148-EL153. [CrossRef] [PubMed]

25. Jeon, J.; Lee, P.; You, J.; Kang, J. Acoustical characteristics of water sounds for soundscape enhancement in urban open spaces. J. Acoust. Soc. Am. 2012, 131, 2101-2109. [CrossRef] [PubMed]

26. Fastl, H.; Zwicker, E. Psychoacoustics: Facts And Models, 3rd ed.; Springer-Nature Inc: Berlin, Germany; New York, NY, USA, 2007.

27. Gelfand, S.A. Hearing: An Introduction to Psychological and Physiological Acoustics, 5th ed.; Informa Healthcare: New York, NY, USA, 2009.

28. International Organization for Standardization. ISO 9613-2:1996-Acoustics-Attenuation of Sound during Propagation Outdoors_-Part 2: General Method of Calculation; International Organization for Standardization: Geneva, Switzerland, 1996.

29. Farina, A. Validation of the pyramid tracing algorithm for sound propagation outdoors: Comparison with experimental measurements and with the ISO-DIS 9613 standards. Adv. Eng. Softw. 2000, 31, 241-250. [CrossRef]

30. Farina, A. Ramsete Home Page. Available online: http://www.ramsete.com/ (accessed on 13 December 2019).

31. International Electrotechnical Commission. IEC 60076-10:2016_Power Transformers_Part 10: Determination of Sound Levels; International Electrotechnical Commission: Geneva, Switzerland, 2016.

32. Badino, E.; Manca, R.; Shtrepi, L.; Calleri, C.; Astolfi, A. Effect of façade shape and acoustic cladding on reduction of leisure noise levels in a street canyon. Build. Environ. 2019, 157, 242-256. [CrossRef]

33. Italian Parliament. Legge 26/10/1995, n. 447-Legge Quadro Sull'inquinamento Acustico (Law 26/10/1995, n. 447-Framework Law on Environmental Noise); Italian Official Gazette General Series n. 254 of 30-10-1995, Ordinary Supplement n. 125; Istituto Poligrafico e Zecca dello Stato: Rome, Italy, 1995. (In Italian)

34. Italian Presidency of the Council of Ministers. D.P.C.M. 14/11/97-Valori Limite delle Sorgenti Sonore (Decree by the Prime Minister of Italy 14/11/1997_Limit Values for Noise Sources); Italian Official Gazette General Series n. 280 of 1-12-1997; Istituto Poligrafico e Zecca dello Stato: Rome, Italy, 1997. (In Italian)

35. Italian Ministry of the Environment. D.M. 16/03/1998-Tecniche di Rilevamento e di Misurazione dell'Inquinamento Acustico (Ministerial Decree 16/03/1998-Techniques for Noise Pollution Detection and Measurement); Italian Official Gazette General Series n. 76 of 01-04-1998; Istituto Poligrafico e Zecca dello Stato: Rome, Italy, 1998. (In Italian)

36. International Electrotechnical Commission. IEC 61672-1:2013-Electroacoustics—Sound Level Meters-Part 1: Specifications; International Electrotechnical Commission: Geneva, Switzerland, 2013.

37. Kurze, U.; Anderson, G. Sound attenuation by barriers. Appl. Acoust. 1971, 4, 35-53. [CrossRef]

38. LecaSistemi. SoundLeca 20 (SL20) Technical Datasheet. Available online: www.lecasistemi.it (accessed on 14 December 2019).

39. Hawkins, T., Jr.; Stevens, S. The Masking of Pure Tones and of Speech by White Noise. J. Acoust. Soc. Am. 1950, 22, 6-13. [CrossRef]

40. Hong, J.; Lam, B.; Ong, Z.T.; Ooi, K.; Gan, W.S.; Kang, J.; Yeong, S.; Lee, I.; Tan, S.T. The effects of spatial separations between water sound and traffic noise sources on soundscape assessment. Build. Environ. 2020, 167. [CrossRef]

(C) 2020 by the authors. Licensee MDPI, Basel, Switzerland. This article is an open access article distributed under the terms and conditions of the Creative Commons Attribution (CC BY) license (http://creativecommons.org/licenses/by/4.0/). 